\title{
A New 3D Coordination Polymer of Bismuth with Nicotinic Acid N-Oxide
}

\author{
Farzin Marandi, ${ }^{1}$ Ingo Pantenburg, ${ }^{2}$ and Gerd Meyer ${ }^{2}$ \\ ${ }^{1}$ Department of Chemistry, Payame Noor University, Tehran 19395-3697, Iran \\ ${ }^{2}$ Department für Chemie, Institut für Anorganische Chemie, Universität zu Köln, Greinstraße 6, 50939 Köln, Germany
}

Correspondence should be addressed to Farzin Marandi; f.marandi@gmail.com

Received 30 May 2013; Accepted 7 August 2013

Academic Editor: Christopher G. Hamaker

Copyright (c) 2013 Farzin Marandi et al. This is an open access article distributed under the Creative Commons Attribution License, which permits unrestricted use, distribution, and reproduction in any medium, provided the original work is properly cited.

\begin{abstract}
The new three-dimensional coordination polymer $\left\{\left[\mathrm{Bi}(\mathrm{NNO})_{2}\left(\mathrm{NO}_{3}\right)\right] \cdot 1.5 \mathrm{H}_{2} \mathrm{O}\right\}_{n}\left(1, \mathrm{NNO}^{-}=\right.$nicotinate $N$-oxide $)$ was synthesized and characterized by elemental analysis, IR and ${ }^{1} \mathrm{H}-\mathrm{NMR}$ spectroscopy, as well as single-crystal X-ray diffraction analysis. $\mathbf{1}$ crystallizes in the monoclinic space group $\mathrm{C} 2 / \mathrm{c}$. The crystal structure consists of a rectangular-shaped grid constructed with $\mathrm{NNO}$ linkers. Cavities of a diameter of 7.9-8.3 $\AA^{2}$ are filled with disordered water molecules. The thermal stability of the compound was evaluated by thermogravimetric analysis.
\end{abstract}

\section{Introduction}

Metal-organic frameworks (MOFs) have currently attracted ever-increasing attention because of their intriguing structural topologies and promising applications as functional materials in magnetism, sorption [1], separation, catalysis [2], and drug delivery [3]. Therefore, there are intense research efforts on the synthesis of such materials, and several metalorganic frameworks with zeolitic structures have been reported [4]. With their versatile bridging modes, carboxylates are often employed as building blocks to construct coordination polymers [5].

Pyridyl carboxylic acids and their $\mathrm{N}$-oxide derivatives are especially useful in this regard, but the exploitation of the ligands in the construction of open framework materials is still in its infancy [6-8]. The anions of these acids may bond to metal centers via their $\mathrm{N}$ - and $\mathrm{O}$ - donor atoms. Thus, one would expect higher flexibility and more versatile coordination modes compared to the original ligand (Scheme 1). Furthermore, the separation of the bridging sites is definitely larger. However, studies on such ligand behavior toward coordination polymers are limited, and only a few transition metal-, lanthanide metal-, and main group metal-based coordination polymers incorporating pyridyl carboxylic acid $N$ oxides have been structurally examined $[9,10]$.
Herein, we describe the synthesis and characterization of a new 3D coordination polymer with nicotinate $\mathrm{N}$-oxide (NNO), $\left\{\left[\mathrm{Bi}(\mathrm{NNO})_{2}\left(\mathrm{NO}_{3}\right)\right] \cdot 1.5 \mathrm{H}_{2} \mathrm{O}\right\}_{n}(\mathbf{1})$. To the best of our knowledge, no systematic investigation of bismuth-based compounds [11] with nicotinic acid $\mathrm{N}$-oxide has been documented [12].

\section{Experimental Details}

Synthesis of $\left\{\left[\mathrm{Bi}(\mathrm{NNO})_{2}\left(\mathrm{NO}_{3}\right)\right] \cdot 1 \cdot 5 \mathrm{H}_{2} \mathrm{O}\right\}_{n}$ (1). All reagents were used as purchased without further purification. Nicotinic acid $\mathrm{N}$-oxide $(0.104 \mathrm{~g}, 0.75 \mathrm{mmoL})$ was placed in one of the arms of a branched tube [13], whereas bismuth(III) nitrate pentahydrate $(0.121 \mathrm{~g}, 0.25 \mathrm{mmoL})$ was placed in the other arm. Methanol and water (ratio 3:1) were carefully added to fill both arms. The tube was sealed and the ligand-containing arm was immersed in a bath at $60^{\circ} \mathrm{C}$, whereas the other maintained at ambient temperature. After two days, crystals that had been deposited in the cooler arm were filtered, washed with acetone and ether, and dried in air (yield: 85\%).

Elemental analyses $(\mathrm{C}, \mathrm{H}$, and $\mathrm{N}$ ) were performed using a Carlo Erba model EA 1108 analyzer: found: C: 20.54, H: $1.13, \mathrm{~N}: 6.58 \%$. Calculated for $\mathrm{C}_{12} \mathrm{H}_{11} \mathrm{BiN}_{3} \mathrm{O}_{10.5}: \mathrm{C}: 20.82, \mathrm{H}$ : $0.99, \mathrm{~N}, 6.94 \%$. FT-IR $\left(\mathrm{cm}^{-1}\right)$ : selected bands: $3443 \mathrm{w}, 3074 \mathrm{w}$, $1617 \mathrm{~m}, 1587 \mathrm{~m}, 1557 \mathrm{~s}, 1382 \mathrm{~s}, 1287 \mathrm{w}, 1208 \mathrm{~m}, 937 \mathrm{~m}, 799 \mathrm{~s}, 760 \mathrm{~m}$, 
<smiles>[M]OC(=O)c1ccc[n+](O[M])c1</smiles>

(a)<smiles>[M]OC(=O)c1ccc[n+]([O-])c1</smiles>

(b)<smiles>[M]OC(O[M])c1ccc[n+]([O-])c1</smiles>

(c)<smiles>[M]OC1OC1c1cccc([N+](O[M])O[M])c1</smiles>

(d)<smiles>[M]OC(O[M])c1ccc[n+]([O-])c1</smiles>

(e)<smiles>[M]O[n+]1cccc(C2O[M]O2)c1</smiles>

This work

Scheme 1: Coordination modes of the nicotinate $\mathrm{N}$-oxide $\left(\mathrm{NNO}^{-}\right)$ligand.

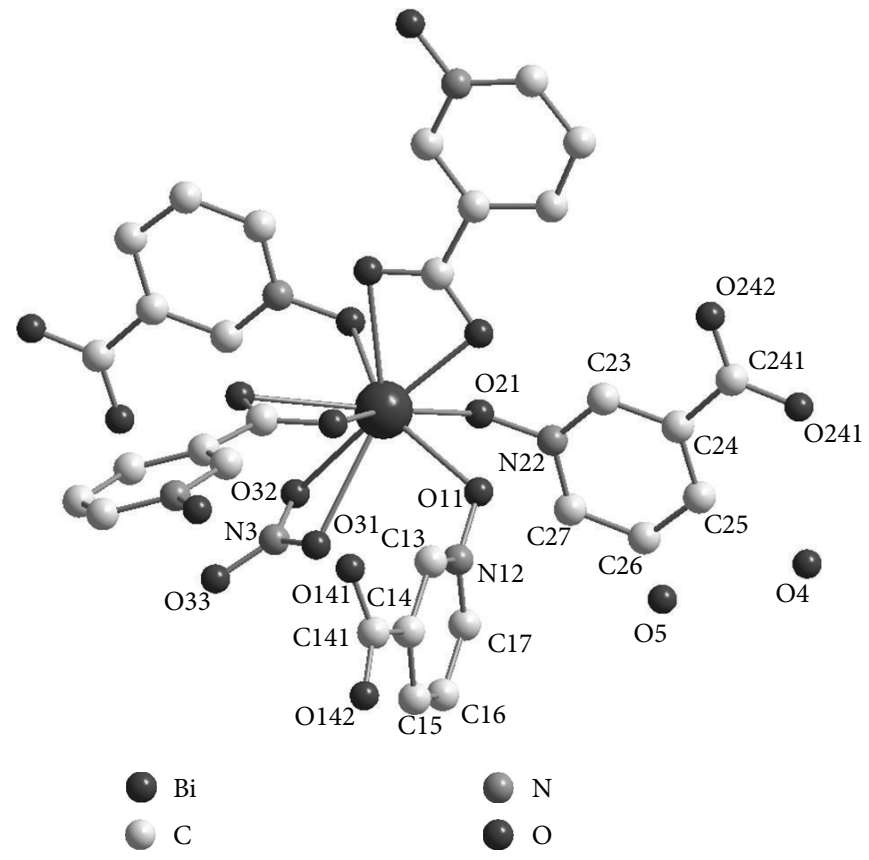

(a)

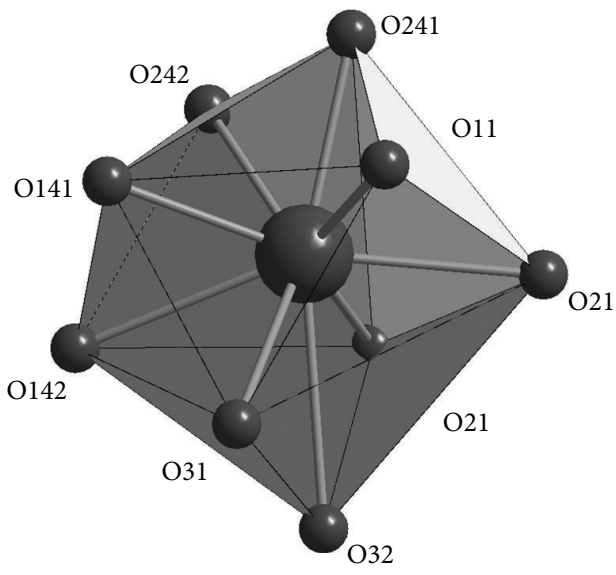

(b)

FIgURE 1: (a) Molecular structure of $\left\{\left[\mathrm{Bi}(\mathrm{NNO})_{2}\left(\mathrm{NO}_{3}\right)\right] \cdot 1.5 \mathrm{H}_{2} \mathrm{O}\right\}_{n}(\mathbf{1})$ and (b) the coordination sphere of the bismuth ion.

$667 \mathrm{w}$, and $448 \mathrm{w}$. Solution ${ }^{1} \mathrm{H}-\mathrm{NMR}$ spectrum was recorded on a Bruker DRX-250 AVANCE spectrometer at $250 \mathrm{MHz}$ using $\left[\mathrm{D}_{6}\right]$ dimethylsulfoxide as the solvent: 8.45 (s, NNO, $1 \mathrm{H}), 8.40(\mathrm{~d}, \mathrm{NNO}, 1 \mathrm{H}), 7.75(\mathrm{~d}, \mathrm{NNO}, 1 \mathrm{H})$, and $7.54(\mathrm{dd}, \mathrm{NNO}$, 1H) $\mathrm{ppm}$.

Thermogravimetric analysis (TGA) was performed in $\mathrm{N}_{2}$ atmosphere with a flow rate of $20 \mathrm{~mL} \mathrm{~min}^{-1}$ on a Seiko Instrument thermal analyzer from 20 to $800^{\circ} \mathrm{C}$, with a heating rate of $10^{\circ} \mathrm{C} \mathrm{min}{ }^{-1}$ in ceramic crucibles.

Data collection for X-ray diffraction single crystal structure determination was performed on a Stoe IPDS 2T diffractometer using graphite-monochromated MoKo radiation $(0.71073 \AA)$. The data were corrected for Lorentz and polarization effects. A numerical absorption correction based on crystal-shape optimization was applied for all data [14]. The programs used in this work are Stoe's X-AREA [15], including X-RED and X-SHAPE for data reduction and absorption correction [16], and the WINGX suite of programs [17], including SIR-92 [18] and SHELXL-97 [19] for structure solution and refinement. The hydrogen atoms were placed in idealized positions and constrained to ride on their parent atoms. The last cycles of refinement included atomic positions for all atoms, anisotropic displacement parameters for all nonhydrogen atoms, and isotropic displacement parameters for all hydrogen atoms. Full cif deposition, excluding structure factor amplitudes, was resided by the Cambridge Crystallography Data CCDC-906828 for $\mathbf{1}$, and copies of the data can be obtained, free of charge, via http://www.ccdc.cam.ac.uk/deposit.

Crystal data of $\left[\mathrm{Bi}(\mathrm{NNO})_{2}\left(\mathrm{NO}_{3}\right)\right] \cdot 1.5 \mathrm{H}_{2} \mathrm{O}$ (1): $\mathrm{C}_{12} \mathrm{H}_{11} \mathrm{BiN}_{3} \mathrm{O}_{10.5}, \quad 574.22 \mathrm{~g} \mathrm{moL}^{-1}$; diffractometer IPDS$2 \mathrm{~T} ; \mathrm{T}=120(2) \mathrm{K} ; 2 \theta_{\max }=54.8^{\circ} ; 0^{\circ} \leq \omega \leq 180^{\circ}, \varphi=$ $0^{\circ} ; 0^{\circ} \leq \omega \leq 180^{\circ}, \varphi=90^{\circ} \Delta \omega=2^{\circ}, 180$ images; $-29 \leq$ $h \leq 29,-16 \leq k \leq 16,-13 \leq l \leq 13 ; \rho_{\text {calc }}=2.267 \mathrm{~g} \mathrm{~cm}^{-3}$; 
TABLE 1: Selected bond lengths $/ \AA$ and angles $/^{\circ}$ for $\left\{\left[\mathrm{Bi}(\mathrm{NNO})_{2}\left(\mathrm{NO}_{3}\right)\right] \cdot 1.5 \mathrm{H}_{2} \mathrm{O}\right\}_{n}(\mathbf{1})$.

\begin{tabular}{|c|c|c|c|}
\hline Bil-O141 $^{\mathrm{i}}$ & $2.323(2)$ & Bil-O241 ${ }^{\text {ii }}$ & $2.326(2)$ \\
\hline Bil-O11 & $2.333(2)$ & Bil-O21 & $2.476(2)$ \\
\hline $\mathrm{Bil}-\mathrm{O} 242^{\mathrm{ii}}$ & $2.557(2)$ & Bil-O21 $1^{\mathrm{iii}}$ & $2.573(2)$ \\
\hline Bil-O142 $2^{\mathrm{i}}$ & $2.584(2)$ & Bil-O31 & 2.611(3) \\
\hline Bil-O32 & $2.816(3)$ & $\mathrm{O} 242^{\mathrm{ii}}-\mathrm{Bi1}-\mathrm{O} 31$ & $141.81(8)$ \\
\hline O141-Bil-O21 & $158.87(8)$ & O241 ${ }^{\mathrm{ii}}$-Bi1-O21 & $81.81(8)$ \\
\hline O11-Bil-O21 & $77.77(8)$ & $\mathrm{O} 141^{\mathrm{i}}-\mathrm{Bi1}-\mathrm{O} 242^{\mathrm{ii}}$ & $75.83(8)$ \\
\hline $\mathrm{O} 241^{\mathrm{ii}}-\mathrm{Bi1}-\mathrm{O} 242^{\mathrm{ii}}$ & $53.30(8)$ & O11-Bil-O242 $2^{\mathrm{ii}}$ & $121.46(8)$ \\
\hline O21-Bil-O242 & $109.84(8)$ & O141 ${ }^{\mathrm{i}}-\mathrm{Bil}-\mathrm{O} 21^{\mathrm{iii}}$ & $133.78(7)$ \\
\hline $\mathrm{O} 241^{\mathrm{ii}}-\mathrm{Bi1}-\mathrm{O} 21^{\mathrm{iii}}$ & $98.58(8)$ & O11-Bi1-O21 $1^{\mathrm{iii}}$ & $143.28(7)$ \\
\hline O21-Bil-O21 ${ }^{\mathrm{iii}}$ & $65.67(8)$ & $\mathrm{O} 242^{\mathrm{ii}}-\mathrm{Bi1}-\mathrm{O} 21^{\mathrm{iii}}$ & $71.12(8)$ \\
\hline O141 $1^{\mathrm{i}}-\mathrm{Bil}-\mathrm{O} 142^{\mathrm{i}}$ & $53.40(8)$ & $\mathrm{O} 241^{\mathrm{ii}}-\mathrm{Bi1}-\mathrm{O} 142^{\mathrm{i}}$ & $120.95(8)$ \\
\hline O11-Bi1-O142 ${ }^{\mathrm{i}}$ & $129.15(8)$ & O21-Bi1-O142 & $147.33(7)$ \\
\hline $\mathrm{O} 242^{\mathrm{ii}}-\mathrm{Bi1}-\mathrm{O} 142^{\mathrm{i}}$ & $74.19(8)$ & $\mathrm{O} 21^{\mathrm{iii}}-\mathrm{Bil}-\mathrm{O} 142^{\mathrm{i}}$ & $86.58(7)$ \\
\hline O141'-Bi1-O31 & $73.64(9)$ & 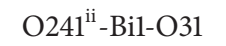 & $144.30(8)$ \\
\hline O11-Bil-O31 & $76.15(8)$ & O21-Bil-O31 & $106.92(8)$ \\
\hline $\mathrm{O} 21^{\mathrm{iii}}-\mathrm{Bi1}-\mathrm{O} 31$ & $116.71(8)$ & $\mathrm{O} 142^{\mathrm{i}}-\mathrm{Bi1}-\mathrm{O} 31$ & $69.35(8)$ \\
\hline
\end{tabular}

i: $-x, y,-z+1 / 2$, ii: $x,-y, z-1 / 2$, iii: $-x+1 / 2,-y+1 / 2,-z$.

and 25057 measured reflections of which 3574 were symmetrically independent; $R_{\text {int }}=0.0832 ; F(000)=2168 ; \mu=$ $10.543 \mathrm{~mm}^{-1}$. Monoclinic, C2/c (no. 15), $a=23.468(1), b=$ 13.334(1), $c=10.912(1) \AA, \beta=99.762(3)^{\circ}, V=3364.9(2) \times$ $10^{6} \AA^{3}$, and $Z=8 ; R$ values: $R_{1} / w R_{2}$ for 3387 reflections with $\left[I_{0}>2 \sigma\left(I_{0}\right)\right]: 0.0205 / 0.0456$, for all data: $0.0219 / 0.0462$; $S_{\text {all }}=1.076$.

\section{Results and Discussion}

Colourless block-shaped crystals of $\left\{\left[\mathrm{Bi}(\mathrm{NNO})_{2}\left(\mathrm{NO}_{3}\right)\right]\right.$. $\left.1.5 \mathrm{H}_{2} \mathrm{O}\right\}_{n}(1)$ were obtained by slow interdiffusion of solutions of $\mathrm{Bi}\left(\mathrm{NO}_{3}\right)_{3} \cdot 5 \mathrm{H}_{2} \mathrm{O}$ and nicotinic acid $\mathrm{N}$-oxide (HNNO) in aqueous methanol under ambient conditions. The crystal structure of 1 may be regarded as a three-dimensional coordination polymer. The coordination environment around the $\mathrm{Bi}^{3+}$ ion is shown in Figure 1 together with the asymmetric unit of the crystal structure; selected interatomic distances are summarized in Table 1 . The bismuth ions center slightly distorted tricapped trigonal prisms with two oxygen atoms of one nitrate anion and seven oxygen atoms of five nicotinate $\mathrm{N}$-oxide anions with $\mathrm{Bi}-\mathrm{O}$ distances between 2.323(2) and 2.816(3) $\AA$ [20] (sum of the ionic radii $\mathrm{Bi}^{3+}$ and $\mathrm{O}^{2-}$ is $2.43 \AA$ ).

The distorted $\left[\mathrm{Bi}-\mathrm{O}_{9}\right]$ polyhedra is hemidirected subject to stereochemically active lone pairs [20], and the presence of stereochemically active lone pairs is commonly observed in bismuth-based coordination compounds [21]. In 1, there are, therefore, relatively short $\mathrm{Bi}-\mathrm{O}$ distances ranging from 2.207(8) to 2.367(8) $\AA$ and rather long Bi-O distances ranging from $2.592(8)$ to $2.743(9) \AA$, as well as bond angles of less than $90^{\circ}$ (ranging from $53.30(8)$ to $86.58(7)^{\circ}$, see Table 1 ).

In 1, five unique $\mathrm{NNO}^{-}$anions adopted two different types of coordination modes, as shown in Figure 2. See Scheme 1 for the known coordination modes of $\mathrm{NNO}^{-}$in

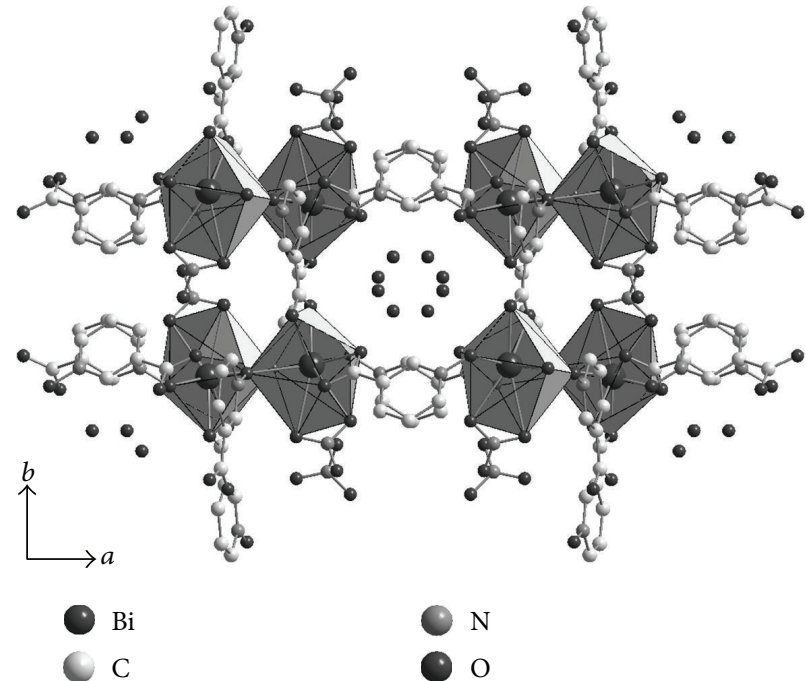

(a)

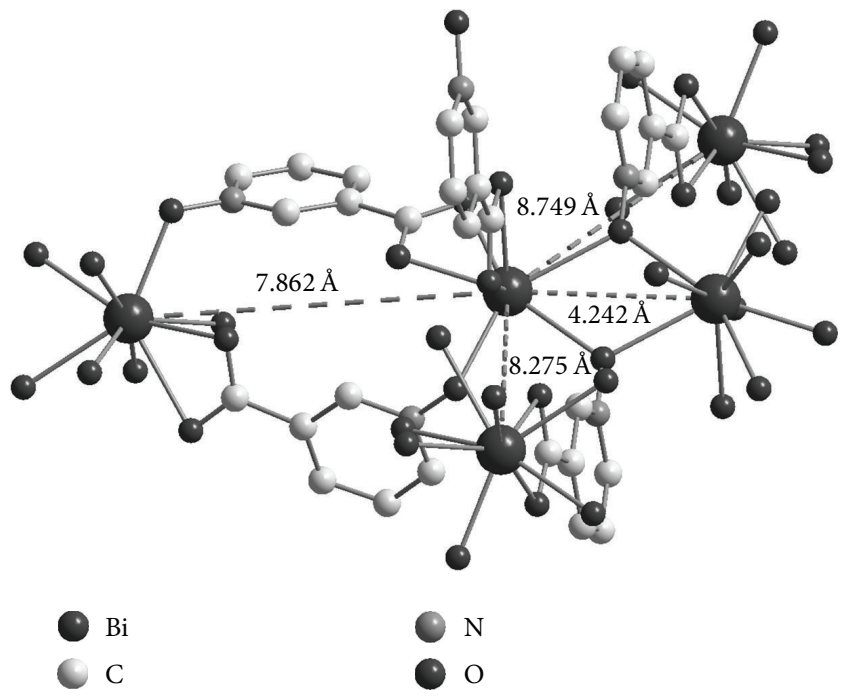

(b)

Figure 2: (a) View of the three-dimensional coordination polymer in the crystal structure of $\mathbf{1}$ along the crystallographic $b$ axis. The guest water molecules are located within the rectangular channels. (b) $\mathrm{Bi}-\mathrm{Bi}$ distances and the coordination modes of the $\mathrm{NNO}^{-}$anions in $\mathbf{1}$.

structurally characterized coordination polymers [22]. One type of the $\mathrm{NNO}^{-}$anions (three $\mathrm{NNO}^{-}$anions) in 1 bridges three $\mathrm{Bi}(\mathrm{III})$ ions. In particular, the $N$-oxide moiety bridges two bismuth ions $(\mu-\mathrm{O})$ with distances of $4.242 \AA$, whereas the carboxylate group forms two bonds, chelating to one $\mathrm{Bi}(\mathrm{III})$ ion (Scheme $1(\mathrm{~d}))$. The other type of the $\mathrm{NNO}^{-}$ anions (two $\mathrm{NNO}^{-}$anions) bridges two bismuth ions through chelating of the carboxylate and coordinating of the $\mathrm{N}$-oxide groups to $\mathrm{Bi}(\mathrm{III})$. The interconnection of the bismuth ions by the $\mathrm{NNO}^{-}$ligands results in the formation of a $3 \mathrm{D}$ network with $\mathrm{Bi}-\mathrm{Bi}$ separations of $4.242,7.862,8.275$, and $8.749 \AA$ (Figure 2(b)). One nitrate anion coordinates to $\mathrm{Bi}(\mathrm{III})$ as a chelating anion. 


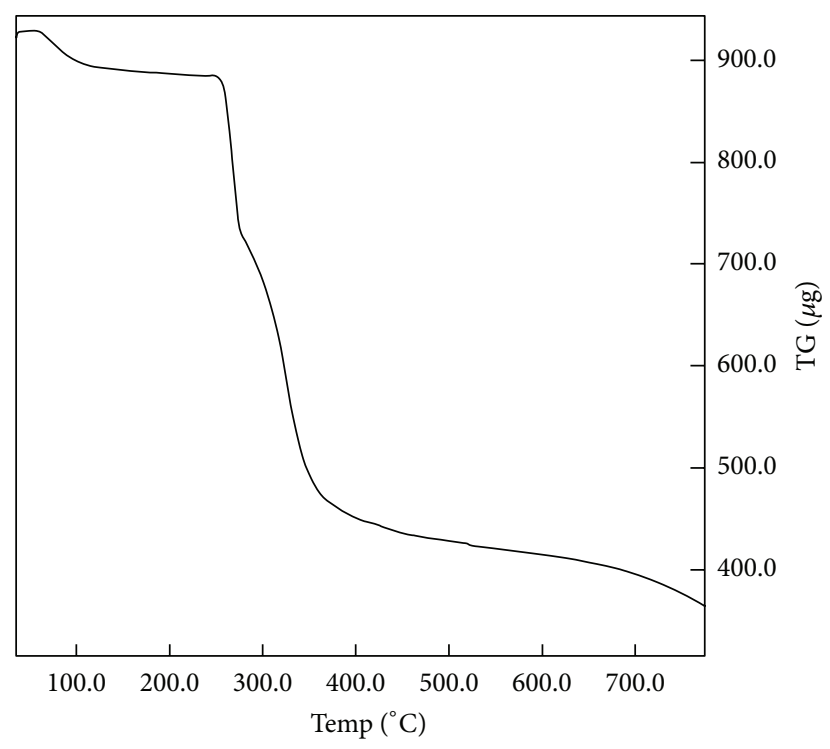

Figure 3: Thermogravimetry curve of $\left\{\left[\mathrm{Bi}(\mathrm{NNO})_{2}\left(\mathrm{NO}_{3}\right)\right] \cdot 1.5 \mathrm{H}_{2} \mathrm{O}\right\}_{n}$ (1).

TABLE 2: Hydrogen bonding in the crystal structure of (1).

\begin{tabular}{lc}
\hline $\mathrm{A} \cdots \mathrm{B}$ & $\mathrm{D}(\mathrm{A} \cdots \mathrm{B}) / \AA$ \\
\hline $\mathrm{O} 4 \cdots \mathrm{O} 4(1-x, 1-y,-z)$ & $2.574(1)$ \\
$\mathrm{O} 241 \cdots \mathrm{O} 11(x, 1-y,-1 / 2+z)$ & $2.739(3)$ \\
$\mathrm{O} 4 \cdots \mathrm{O} 5(x, 1-y,-1 / 2+z)$ & $2.775(2)$ \\
$\mathrm{O} 4 \cdots \mathrm{O} 241(1-x, y, 1 / 2-z)$ & $2.983(8)$ \\
\hline
\end{tabular}

Encapsulated in the $\mathrm{Bi}(\mathrm{III})-\mathrm{NNO}$ framework, there are uncoordinated, disordered water molecules in the crystal structure of 1 . The bridging $\mathrm{NNO}^{-}$ligands are arranged in conjunction with weak $\pi-\pi$ stacking interactions of the pyridine rings (distances between the rings are $3.440 \AA$ ) [23]. The rectangular-shaped grid, formed by $\mathrm{NNO}^{-}$anions and bismuth ions, gives rise to the large rectangular cavities known among noninterpenetrating structures [24], with approximate cavity sizes of $7.9-8.3 \AA^{2}$. One and a half crystallographically unique water molecules are trapped within these channels. As shown in Figure 2, uncoordinated water molecules and the carboxylate oxygen atoms of the $\mathrm{NNO}^{-}$ligands are involved in hydrogen bonding interactions (Table 2). The topology of the three-dimensional bismuth(III)-coordination polymer may be characterized (by TOPOS program) by the point symbol for the net as follows: $\left\{3^{3} \cdot 4^{5} \cdot 5^{6} \cdot 6\right\}$.

Thermogravimetric analysis (TGA) was performed applying polycrystalline samples under nitrogen atmosphere to get an idea of the thermal stability of $\left\{\left[\mathrm{Bi}(\mathrm{NNO})_{2}\left(\mathrm{NO}_{3}\right)\right]\right.$. $\left.1.5 \mathrm{H}_{2} \mathrm{O}\right\}_{n}$ (1), see (Figure 3). The first weight loss at 85$115^{\circ} \mathrm{C}$ in the TG curve corresponds to the loss of water molecules (calcd. 4.70\%). Decomposition of the framework is characterized by an intense exothermic peak $\left(270^{\circ} \mathrm{C}\right)$ followed by another weak exothermic peak $\left(320^{\circ} \mathrm{C}\right)$. Accordingly, a rapid mass loss occurs between 270 and $350^{\circ} \mathrm{C}$ in the TG curve corresponding to $50 \%$ of the original sample mass. Coordination polymer $\mathbf{1}$ appears to decompose completely during this transition, presumably leaving a final residue of $\mathrm{Bi}_{2} \mathrm{O}_{3}$ (found $41.20 \%$, calcd. $40.59 \%$ ). The mass loss calculations as well as the microanalyses (atomic absorption) of the solid residues suggest that the residue left as a final decomposition product of the complexes is $\mathrm{Bi}_{2} \mathrm{O}_{3}$. IR analysis of the final residue (at $700^{\circ} \mathrm{C}$ ) revealed none of the characteristic absorption bands of 1 . In addition, the presence of absorption peaks at $421,500,541$, and $845 \mathrm{~cm}^{-1}$ in the IR spectrum provides evidence for the identity of the residue as $\mathrm{Bi}_{2} \mathrm{O}_{3}$ [25].

\section{Conclusions}

In this paper, with $\left\{\left[\mathrm{Bi}(\mathrm{NNO})_{2}\left(\mathrm{NO}_{3}\right)\right] \cdot 1.5 \mathrm{H}_{2} \mathrm{O}\right\}_{n}\left(\mathrm{NNO}^{-}=\right.$ nicotinate $\mathrm{N}$-oxide, 1 ), a new three-dimensional coordination polymer is reported. Channels are formed by bridging of the $\mathrm{NNO}^{-}$ligands, representing a new coordination mode. Uncoordinated and disordered water molecules are trapped within the rectangular channels. These water molecules and the carboxylate $\mathrm{O}$-atom of the $\mathrm{NNO}^{-}$ligands are involved in hydrogen bonding interactions. This three-dimensional coordination polymer appears to represent the first crystal structure of bismuth(III) with nicotinic acid $\mathrm{N}$-oxide.

\section{Acknowledgment}

This investigation supported by Iran National Science Foundation (INSF) is gratefully acknowledged by Farzin Marandi.

\section{References}

[1] Z. Yin, Q.-X. Wang, and M.-H. Zeng, "Iodine release and recovery, influence of polyiodide anions on electrical conductivity and nonlinear optical activity in an interdigitated and interpenetrated bipillared-bilayer metal-organic framework," Journal of the American Chemical Society, vol. 134, no. 10, pp. 4857-4863, 2012.

[2] K. Sumida, D. L. Rogow, J. A. Mason et al., "Carbon dioxide capture in metal-organic frameworks," Chemical Reviews, vol. 112, no. 2, pp. 724-781, 2012.

[3] X. Chen, H.-X. Li, Z.-Y. Zhang, W. Zhao, J.-P. Lang, and B. F. Abrahams, "Activation and amplification of the third-order NLO and luminescent responses of a precursor cluster by a supramolecular approach," Chemical Communications, vol. 48, no. 37, pp. 4480-4482, 2012.

[4] S. Mandal and S. Natarajan, "Inorganic-organic hybrid structure: synthesis, structure and magnetic properties of a cobalt phosphite-oxalate, $\left[\mathrm{C}_{4} \mathrm{~N}_{2} \mathrm{H}_{12}\right]\left[\mathrm{Co}_{4}\left(\mathrm{HPO}_{3}\right)_{2}\left(\mathrm{C}_{2} \mathrm{O}_{4}\right)_{3}\right]$," Journal of Solid State Chemistry, vol. 178, no. 7, pp. 2376-2382, 2005.

[5] H.-C. Zhou, J. R. Long, and O. M. Yaghi, "Introduction to metalorganic frameworks," Chemical Reviews, vol. 112, no. 2, pp. 673674, 2012.

[6] J. J. Henkelis, S. A. Barnett, L. P. Harding, and M. J. Hardie, "Coordination polymers utilizing $N$-oxide functionalised host ligands," Inorganic Chemistry, vol. 51, no. 20, pp. 10657-10674, 2012.

[7] L. L. Wen, D. B. Dang, C. Y. Duan, Y. Z. Li, Z. F. Tian, and Q. J. Meng, "1D helix, 2D brick-wall and herringbone, and $3 \mathrm{D}$ interpenetration d10 metal-organic framework structures 
assembled from pyridine-2,6-dicarboxylic acid $\mathrm{N}$-oxide," Inorganic Chemistry, vol. 44, no. 20, pp. 7161-7170, 2005.

[8] Z. Hnatejko, G. Dutkiewicz, M. Kubicki, and S. Lis, "New complexes of cobalt(II) ions with pyridinecarboxylic acid $N$-oxides and 4,4' -byp," Journal of Molecular Structure, vol. 1034, pp. 128133, 2013.

[9] Y.-H. Zhao, H.-B. Xu, K.-Z. Shao, Y. Xing, Z.-M. Su, and J.-F. $\mathrm{Ma}$, "Syntheses, characterization, and luminescent properties of three 3D lead-organic frameworks with 1D channels," Crystal Growth \& Design, vol. 7, pp. 513-520, 2007.

[10] R. Sarma, A. Karmakar, and J. B. Baruah, "N-oxides in metalcontaining multicomponent molecular complexes," Inorganic Chemistry, vol. 47, no. 3, pp. 763-765, 2008.

[11] N. Soltanzadeh and A. Morsali, "Sonochemical synthesis of a new nano-structures bismuth(III) supramolecular compound: new precursor for the preparation of bismuth(III) oxide nanorods and bismuth(III) iodide nano-wires," Ultrasonics Sonochemistry, vol. 17, no. 1, pp. 139-144, 2010.

[12] A. Thirumurugan, W. Li, and A. K. Cheetham, "Bismuth 2,6-pyridinedicarboxylates: assembly of molecular units into coordination polymers, $\mathrm{CO}_{2}$ sorption and photoluminescence," Dalton Transactions, vol. 41, no. 14, pp. 4126-4134, 2012.

[13] F. Marandi, P. Hassanmohammadi, H.-K. Fun, and C. K. Quah, "Syntheses and crystal structures of two 3D lead(II) coordination polymers with isonicotinic acid $N$-oxide and pseudohalides," Zeitschrift für Anorganische und Allgemeine Chemie, vol. 638, no. 2, pp. 461-465, 2012.

[14] X-SHAPE 1.06, Crystal Optimisation for Numerical Absorption Correction, Stoe \& Cie, Darmstadt, Germany, 1999.

[15] X-Area 1.16, Stoe Data Absorption Correction Program, Stoe \& Cie, Darmstadt, Germany, 2003.

[16] X-Red 1.22, Stoe Data Reduction Program, Stoe \& Cie, Darmstadt, Germany, 2001.

[17] L. J. Farrugia, "WinGX suite for small-molecule single-crystal crystallography," Journal of Applied Crystallography, vol. 32, pp. 837-838, 1999.

[18] A. Altomare, G. Cascarano, C. Giacovazzo, and A. Guagliardi, "Completion and refinement of crystal structures with SIR92," Journal of Applied Crystallography, vol. 26, no. 3, pp. 343-350, 1993.

[19] G. M. Sheldrick, SHELX-9, Programs for Solution and Refinement of Crystal Structures, Göttingen, Germany, 1997.

[20] A. C. Wibowo, M. D. Smith, J. Yeon, P. S. Halasyamani, and H.C. zur Loye, "Novel 3D bismuth-based coordination polymers: synthesis, structure, and second harmonic generation properties," Journal of Solid State Chemistry, vol. 195, pp. 94-100, 2012.

[21] A. C. Wibowo, M. D. Smith, and H.-C. Zur Loye, "New 3D bismuth-oxo coordination polymers containing terephthalatebased ligands: observation of $\mathrm{Bi}_{2} \mathrm{O}_{2}$-layer and $\mathrm{Bi}_{4} \mathrm{O}_{3}$-chain motifs," CrystEngCommunity, vol. 13, no. 2, pp. 426-429, 2011.

[22] Y.-H. Zhao, H.-B. Xu, Y.-M. Fu et al., "A series of lead(II)organic frameworks based on pyridyl carboxylate acid $N$-oxide derivatives: syntheses, structures, and luminescent properties," Crystal Growth and Design, vol. 8, no. 10, pp. 3566-3576, 2008.

[23] X. Li, W. Zhao, Y. Zhang et al., "Synthesis, structures, and properties of two helical structures from rigid carboxylate ligand and flexible N-bridging ligands," Zeitschrift für Anorganische und Allgemeine Chemie, vol. 638, no. 5, pp. 785-790, 2012.

[24] R. F. Wu and T. L. Zhang, "Synthesis and characterization of a metal-organic coordination polymer," Zeitschrift für anorganische und allgemeine Chemie, vol. 638, no. 2, pp. 282-285, 2012.
[25] V. Dimitrov, Y. Dimitreiv, and A. Montenero, "IR spectra and structure of $\mathrm{V}_{2} \mathrm{O}_{5}-\mathrm{GeO}_{2}-\mathrm{Bi}_{2} \mathrm{O}_{3}$ glasses," Journal of NonCrystalline Solids, vol. 180, no. 1, pp. 51-57, 1994. 

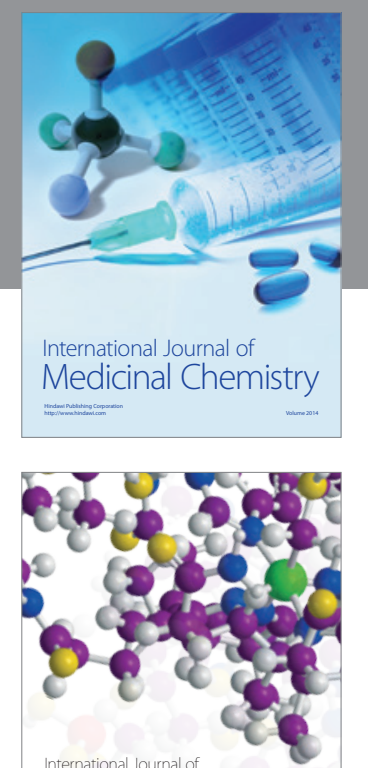

\section{Carbohydrate} Chemistry

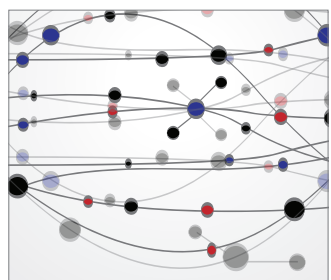

The Scientific World Journal
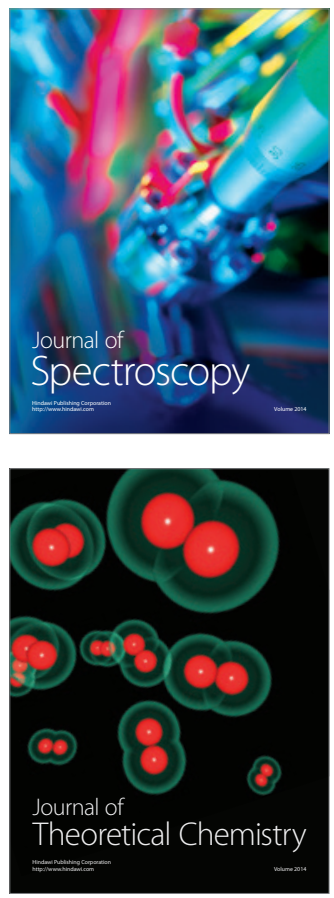
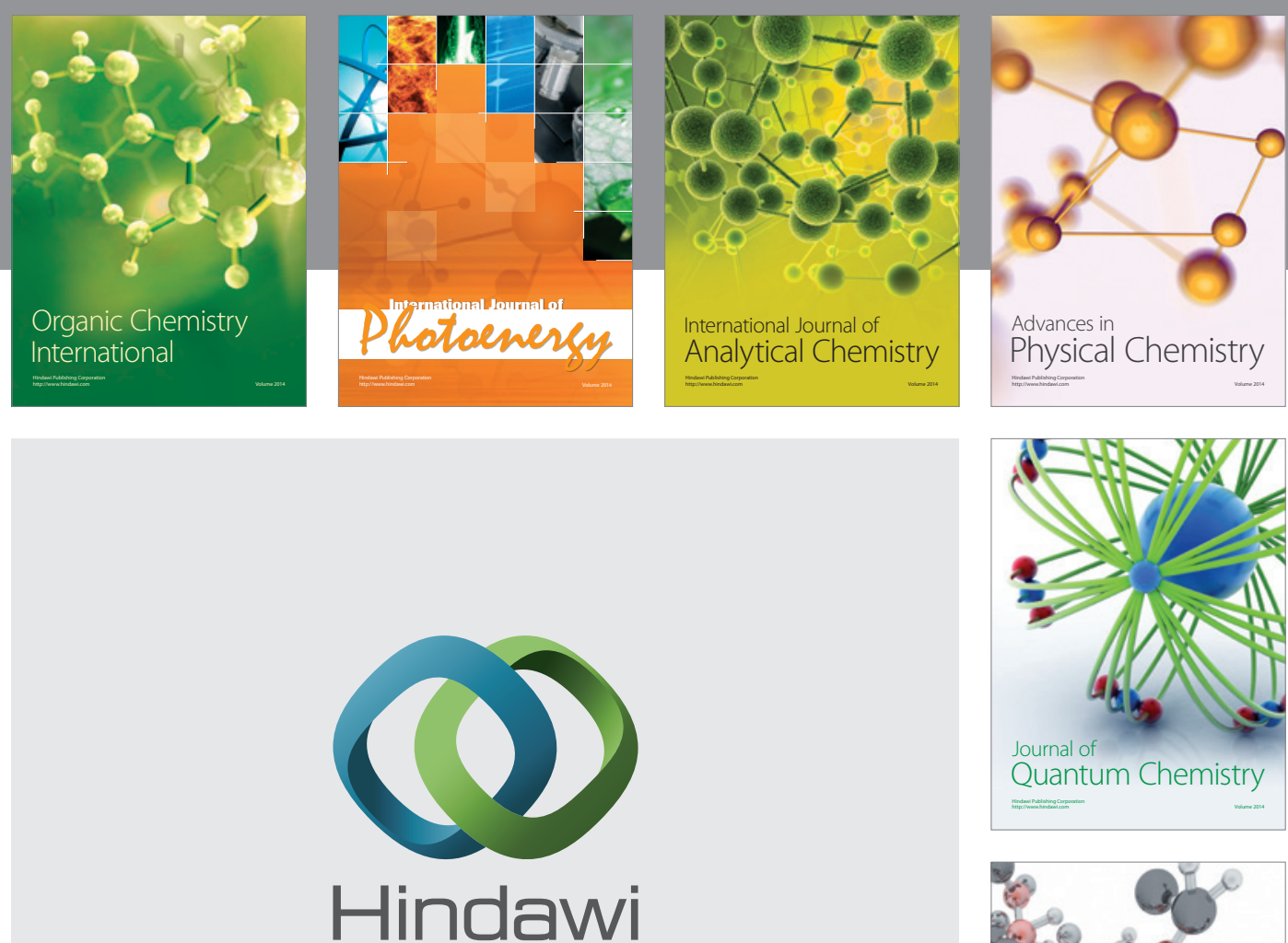

Submit your manuscripts at

http://www.hindawi.com

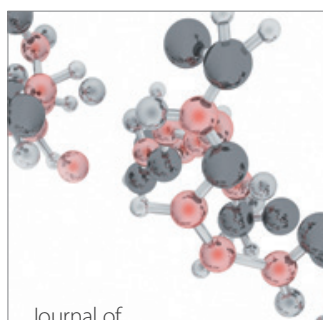

Analytical Methods

in Chemistry

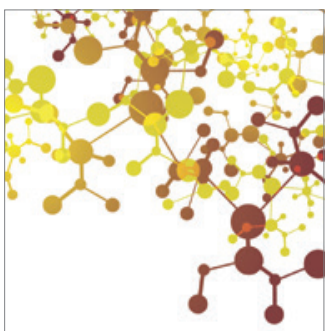

Journal of

Applied Chemistry

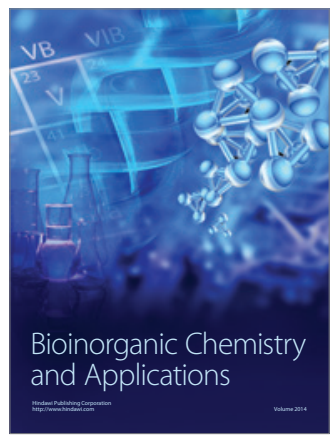

Inorganic Chemistry
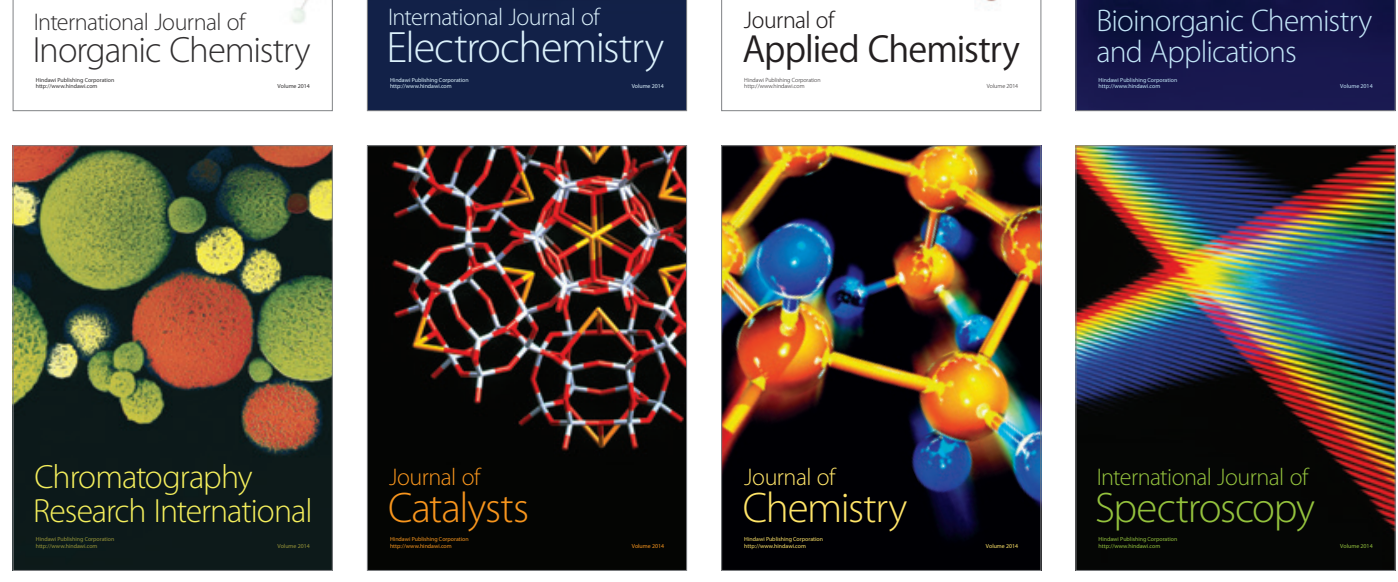